\title{
JOSEPH BEUYS Y EL TODO DIALÉCTICO
}

Data recepción: 2014/01/21

Data aceptación: 2014/07/15

Contacto autora: mortuzar@uvigo.es
Mónica Ortuzar González

Universidade de Vigo

\section{RESUMEN}

En los innumerables artículos de y sobre Joseph Beuys que se han escrito encontramos insistentemente un modelo de frase con la que se plantea su propuesta de Arte en el pensamiento dialéctico occidental y sobre todo con sus lecturas de juventud: Hegel, los Románticos y el cristianismo.

Palabras clave: analizar, pensamiento, arte, filosofía, historia

\section{ABSTRACT}

The countless articles by and about Joseph Beuys invariably feature a mode of thought that frames approaches to his art in terms of Western dialectical thought and specifically the readings of his youth: Hegel, the Romantics and Christianity.

Keywords: analyse, thought, art, philosophy, history

A poco que leamos los innumerables artículos de y sobre Joseph Beuys, que en todos los idiomas y por críticos de todas las tendencias se han escrito, encontramos recogidas repetidamente frases siguiendo el modelo que se traduce en castellano como "Todo..." y que coincide con el reiteradamente empleado por la filosofía anterior a Beuys. Este texto que nos ocupa pretende ser un acercamiento y un comentario a tales frases. El interés de las mismas dentro del pensamiento, la obra $y$, en general, el conocimiento de la figura beuysiana son fundamentales ya que sitúan al artista en relación con el pensamiento alemán del que es deudor directo, principalmente de Hegel y el grupo de los Románticos.

Beuys los conocía desde sus lecturas de juventud y, claro está, desde su vivencia más tradicional aprehendida en su pueblo natal de Kleve donde, además y paralelamente, se vivía fervorosamente el catolicismo. Todo ello se nos presenta tan abigarradamente junto que es difícil separar lo que corresponde exclusivamente a lo beuysiano de todo lo demás.
La concepción artística de Beuys se incluye en el modelo de pensamiento dialéctico occidental de la actualidad que, a su vez, ha sido generado a partir de Heráclito en la antigua Grecia. Siguiendo este modelo hasta nuestros días, pasamos por la cultura europea que tan directamente influyó sobre Beuys: el cristianismo, junto con la tradición alemana de Hegel y los Románticos. Heráclito defendía que el Universo es un continuo devenir en una lucha de contrarios por la que se llega al equilibrio de lo real. Estos contrarios, en el fondo, mantienen desde siempre una profunda unidad mientras las cosas, el mundo, estarían en constante transformación y cambio irracional. Se trata de un planteamiento 500 años anterior a Cristo y es antecesor de Platón, a su vez maestro directo de los pensadores dialécticos que comparten interés por el devenir constante de lo fluido. Para Platón lo real es aquello de los fenómenos que se puede conocer, es decir, que ya consideraba un cierto poso de permanencia con que analizar lo que fluye. Este dato es puente directo para Hegel y la fenomenología, que entiende los cambios de la realidad 
desde las capacidades de los individuos, y nos llegará a través de ambos pensamientos como herramienta para interpretar nuestra percepción tras sucesivas transformaciones dialécticas a lo largo de los siglos.

Inmediatamente tras el pensamiento griego, y diferenciándose de él, aparece el cristianismo dentro de una etapa de dominio aún romano en que se daba a la vez una pluralidad de escuelas filosóficas. El cristianismo, en nuestros días transformado tras una continuada depuración y autointerrogatorio generados desde sí y desde la filosofía, dio lugar a los primeros encargos del Beuys recién vuelto de la guerra que empieza a trabajar como escultor en su pueblo de Kleve. Se trata de tumbas y estelas funerarias, generalmente cruces, que a veces provenían de la tradición simbólica celta y eran pedidas para los panteones de las familias de la zona. El cristianismo, como movimiento religioso, mantiene desde sus inicios una parte de afirmación de la creación y otra parte de negación en cuanto a su surgimiento de la nada. Beuys elegirá también pensar el mundo como algo siempre en proceso y, derivándose de ello, apostará por la necesidad de marchar siempre adelante, hacia una meta marcada por un vector en positivo. Se trata, una vez más, de una concepción de superación fluida, que es en sí misma un modelo de dialéctica antes que una búsqueda de verdad definitiva.

La toma de riendas de Beuys, como líder carismático que era, dirigiendo y haciendo participar a grandes grupos de toda índole (espectadores, estudiantes, coleccionistas, etc.) hacia una meta que, más o menos clara, deja vislumbrar como visionario, como mesías, como chamán, como profesor, o disfrazado de cualquier otra manera que le posibilite una jefatura apoyada en el carisma que siempre lo acompañó, resulta muy propia de él. Por ejemplo hizo un viaje a Manresa, cerca de Barcelona, para conocer de cerca el pueblo y el monasterio de Montserrat, donde San Ignacio de Loyola había escrito sus "Ejercicios Espirituales", en 1523, durante una estancia para curarse de sus heridas de guerra. Es comprensible que Beuys estuviera interesado por el paralelismo compartido con el santo ya que ambos vivieron una etapa de guerreros seguida de otra de ascetas: San Ignacio fundando los jesuitas y Beuys explayando unos ejercicios curativos que había perfeccionado dentro de la disciplina del arte, necesarios para cualquier excombatiente depresivo.

Tras este viaje, el 15 de diciembre de 1966, realizará la acción "Manresa" junto con Henning Christiansen y Björn Nörgard en la Galería Schmela de Düsseldorf. En una habitación donde estaba parte del público (otra parte estaba fuera de la galería) Beuys situó el denominado "Elemento 1", que era una gran cruz partida longitudinalmente, y el "Elemento 2", una caja llena de aparatos que también denomina "Caja Fluxus". En sendas esquinas hay una esquina de grasa y otra de fieltro y algunos aparatos más. Los dos artistas, acompañados de acordes musicales y pronunciando palabras como la pregunta: ¿Dónde está el "Elemento 3"? trabajan sobre todos los objetos presentes manipulándolos.

El pensamiento de Beuys concreta en esta pieza una polarización entre el "Elemento 1" y el "Elemento 2" y su síntesis, el "Elemento 3". En ella se establecen dos principios racionales entendidos a la manera de cristalizaciones típicas y enfrentados a los principios intuitivos que tienden a ser orgánicos. Ambos son habituales en su trabajo y, para reunirlos, utiliza el concepto de Creatividad cósmica, un modelo creativo que tiene mucho de cristiano, donde los pares de opuestos vienen dados por la naturaleza universal de la que el hombre se diferencia porque puede intervenir como "otro" creador fáctico de energías mediante la manipulación de las mismas. En esta y muchas de sus acciones, Beuys se adhiere al incomparable marco que le da Fluxus, una modalidad artística de acción Happening trasladada de América a Europa en la década de los 60 donde se le aporta música además de la presencia del espectador.

Este tipo de polarizaciones dialécticas con un elemento resultante de su acción provienen, además del cristianismo, de la dialéctica de Hegel establecida a principios del s. XIX e inmediatamente anterior al movimiento Romántico. El planteamiento de Hegel de la dialéctica consiste básicamente en partir de una contradicción interna del mundo existente expresada en pares polares de opuestos y dentro de una necesidad de superar los límites presentes ("¿Dónde está 
el 'Elemento 3'?", como se preguntaba Beuys en Manresa). La realidad entendida como un todo de singularidades diferenciadas: Tesis/Antítesis/Síntesis son los tres pasos del movimiento dialéctico aquí recogidos como continuará entendiendo posteriormente Heidegger la obra de arte "arrojada ahí, en el mundo", en una fenomenología donde ya no queda Dios, la obra incluso arrojada fuera del hombre como si estuviera abandonada a su suerte sin tener en cuenta que el espectador la recibe activándola de nuevo, poniéndola otra vez en un par dialéctico (espectador/obra) donde se reavivan las características y el movimiento dados por el autor a la obra originariamente. La separación entre Hegel y Heidegger es poco más de un siglo, y el segundo se nos aparece deudor del planteamiento hegeliano cuando divide los 3 momentos del ser: "ser ahí" y "ser fuera de sí" se corresponden con tesis y antítesis, estar en el mundo y salirse fuera de su ser para ese estar en el mundo, y un tercer momento con la meta puesta en la realización como resultado, el "ser para sí", la reunión de dentro y fuera, del mundo y de la pieza en su propio ser.

Pues bien, cada uno de estos movimientos se puede considerar desde Hegel como una Totalidad, como un Todo dialéctico. Los Románticos, más juguetones en sus definiciones, hablaban metafóricamente del paso entre las 3 etapas del desarrollo del capullo, la flor y el fruto, o también el gusano, el insecto, el animal vertebrado. En cualquier caso la deriva dialéctica lleva a un tercer estadio donde se encuentran superados los dos anteriores. Esta síntesis, o tercer estadio, se abre según el progreso a que tienda el movimiento dialéctico en la continuidad del movimiento polarizado (tesis/antítesis) léase en la pieza "Manresa" como ("Elemento 1"/"Elemento $2 "$ ).

También en la religión cristiana se plantea a Dios como fruto (Espíritu Santo) de la dialéctica entre Padre e Hijo, como una idea que se enajena mediante la encarnación y se convierte así en Trinidad; es en y para sí de la totalidad global. En la "Fenomenología del Espíritu", la suma de contradicciones morales da lugar a una desembocadura en el "Espíritu Absoluto". Pero este desenlace, como ocurre con todas las sín- tesis dialécticas está vivo sólo mientras aguante la contradicción en sí mismo, es decir, que no se disuelve en el resultado sino que ha de seguir activo para mantener su fuerza.

Como dice el estudioso de Hegel, Ernst Bloch, con respecto a la razón pensante de Hegel: "Todo desaparece en el movimiento dialéctico espiritual, todo se conserva en lo que tiene de universal y de particular"1, refiriéndose a que nada se pierde en un pensamiento a la manera dialéctica, puesto que el elemento inicial, sea cual sea, y siempre iniciador de ese pensamiento, se articula exactamente con su contrario $u$ opuesto y crea un movimiento que los desarrolla en su relación infinitamente activa y productiva. Incluso en el caso de cese de este movimiento se produce como resultado lo recogido durante la actividad hasta ese momento de Síntesis, como es el caso del Espíritu o Tercer Elemento hegeliano o, también, el tercer elemento de la Trinidad cristiana.

A renglón seguido encontramos una cita de Hegel para ilustrar que, en la dialéctica, todo desaparece en el movimiento a la vez que todo se conserva en lo que tiene de universal y peculiar: "En cada fase de las ulteriores determinaciones eleva toda la masa de su anterior contenido y no sólo no pierde nada ni deja nada atrás, en su marcha dialéctica, sino que arrastra consigo todo lo adquirido y se enriquece y condensa dentro de sí" 2 . Esto es la realidad Absoluta a que se refiere Hegel. El "Todo" de estas frases, aplicables como veremos también a Beuys hay que escribirlo con mayúsculas puesto que se refiere a un auténtico TODO, a una Totalidad Absoluta y contenedora de lo que es y de lo que se va generando en su propia actividad continua, al mismo tiempo autocontenedora y autogeneradora donde nada se pierde, una especie de maquinaria imparable y absorbedora incluso de sus propios resultados para seguir su movimiento siempre hacia delante, ampliando la Totalidad que por eso es Absoluta, para dar lugar a nuevos pares dialécticos, nuevas síntesis, etc.

Citando nuevamente a Bloch, "El arte vence a la impotencia de la naturaleza, cuyas formas son siempre imperfectas" 3 . Poco más adelante amplía la frase anterior: "Hegel habla del arte desde dentro como una manifestación, no como 
concepto. La obra de arte como una experiencia sensible, tan importante como la idea que en ella aparece" ${ }^{4}$, un acercamiento al arte como percepción que dará origen a la fenomenología contemporánea y, en consecuencia, al interés de Beuys por alejarse de lo tradicional que es también el nuestro.

Lo que se nos aparece a través del arte sería para Hegel, como había sido para el poeta romántico Novalis, objeto de mejora con respecto a la naturaleza, al contrario que en otro romántico, Schelling, que defendía un modelo estético de "naturaleza en Dios". Pocos años antes Hegel ya se había dado cuenta de que el concepto no puede echar a andar por sí mismo él solo. Este es el problema de la puesta en marcha del movimiento dialéctico añadido al factor de la totalidad, el abarcarlo todo, el perfecto "ser para sí", el "absoluto", mientras que su opuesto es lo fragmentario, lo inacabado, lo finito. La necesidad del movimiento dialéctico se encuentra en la fricción entre fragmento y totalidad dentro de la primera polaridad de opuestos.

A propósito de este movimiento dialéctico en tres tiempos incluiré un ejemplo que nos brindó el escultor vasco Jorge Oteiza en una visita a su casa-taller de Alzuza en 1987: la puesta en marcha de la escultura llamada "Par móvil" (1956, dos medias lunas de aluminio unidas por el punto áureo), empujándolo hacia nosotros de tal modo que teníamos que movernos en el estrecho pasillo que quedaba entre las innumerables piezas del taller si no queríamos que la pequeña escultura activada como arma arrojadiza se nos echara encima. Esta pequeña pieza tridimensional, una vez puesta en movimiento, no se pararía nunca, como corresponde a la definición de movimiento dialéctico, excepto por la fuerza de rozamiento.

La cita a Oteiza no es casual: hay más piezas similares entre Oteiza y Beuys como es la "Piedra para jardín contra muro ciego", también de 1956, en hierro y piedra ${ }^{5}$. Esta pieza guarda gran parecido con la de Beuys "Schlitten" (Trineo), de 19696. El "Trineo" es también uno de los elementos que integran la instalación "Das Rudel" (La manada), de 1969, que se puede visitar en la colección permanente del Staatliche Museen Kassel.
Si la pieza de Oteiza consigue un sentido espacial desde sus hierros y los huecos de la piedra, la de Beuys es un objeto a su vez integrado por objetos de supervivencia (una manta de fieltro, una linterna, un trozo de grasa) que mantiene similitud con la anterior en los brazos de prolongación que recogen todo el trineo, mientras la "Piedra para jardín contra muro ciego" es un objeto escultórico donde el elemento central es la piedra horadada y recortada en planos como autocobijo entendido desde la forma y sus prolongaciones en el par (interno/externo). En la instalación de Beuys muchos trineos descienden de una furgoneta como animales portadores de lo necesario para emprender un largo viaje.

Ambas piezas hablan del movimiento. La de Oteiza plantea la rotura de su estabilidad mediante la prolongación de líneas espaciales, y la de Beuys, 13 años posterior, lo hace desde la utilidad que se da a los trineos tanto si se presentan aislados como en grupo. El "Par móvil" de Oteiza es autónomo, lleva implícito el movimiento que se pone en marcha en cuanto alguien lo empuja. No pararía, por definición, hasta el infinito, si no fuera por la fuerza contraria del rozamiento. La "Piedra para jardín contra muro ciego" tampoco tiene límites en cuanto a la aprehensión espacial que la caracteriza incluso desde su estatismo. El "Trineo" de Beuys es un objeto visible cuando se presenta solo, aunque luego se refugie en el grupo, en la manada, donde se aprecia el movimiento hacia una marcada dirección saliendo de la furgoneta con más facilidad que cuando se presenta como un objeto individual al que entendemos con capacidad para deslizarse sobre la nieve. Esta vez es un movimiento representado por el vector hacia delante, no implícito en las dos esculturas de Oteiza.

Vemos que el movimiento dialéctico, tal y como aparece ejemplificado en estas 3 piezas, incluso desde lo más físico, necesita de una mano externa que lo inicie. El artista no sólo es el creador que, semejante a un dios se convierte en activador de las piezas. Tanto el par móvil como la piedra que abre el muro ciego o el grupo de trineos descendiendo del vehículo es una totalidad, una obra de arte diferente, pero también cada una de ellas sirve para ejemplificar el presupuesto hegeliano de movimiento. 
Hegel se acercó de nuevo a posturas abandonadas por la llustración recogiendo las del cristianismo en planteamientos de frases como "Sin el mundo, Dios no es Dios"7 donde se hace patente un reconocimiento al Creador, pero solo desde la deuda con lo creado, con lo que está en el mundo. Lo que es en el mundo a su vez "está" en él y se mantiene en deuda con ése mismo creador con minúsculas, el autor de las obras de arte. Dios es, entonces, creador de lo que nos llega a los sentidos y en cuyo ejercicio se involucra particularmente a su creador que puede, incluso, coincidir con que sea su usuario. Aquí confluye nuestro doble interés en la figura de Hegel, primero como filósofo de la totalidad y de la realidad absoluta (en cuanto a su empleo del pensamiento dialéctico) y, segundo, como filósofo que contempla propuestas dirigidas específicamente al arte ${ }^{8}$.

Se trata de un camino reversible entre lo que Hegel mismo calificaba como polaridad formada por finito e infinito. Lo real se correspondería en Hegel con lo infinito, mientras lo finito sería un momento divisible de ese infinito. Así, este momento, el objeto finito, constituiría el objeto de toda filosofía y lo real absoluto. El objeto filosófico que queremos analizar halla, pues, su lugar tras hacer un corte transversal en todas las capas superpuestas que ha originado el movimiento dialéctico. Posteriormente Hegel amplía su frase anterior: "tan cierto es que existe Dios como que existo yo. Mi ser y el ser divino forman una conexión, y la relación está constituida por el ser" ${ }^{\prime \prime}$. De esta manera define lo que existe dentro de la ontología, el estudio del ser y su enmarque en una existencia que envuelve al todo: lo finito junto con lo infinito, ambos interconectados en una relación de realidad absoluta que vamos a escribir como un par polar cerrado: (finito/infinito). Más interconexión no puede haber. Como decía Ritter, el romántico fundador de la electroquímica, "Todo es, pero es ser será"10, frase útil para establecer el vector hacia el futuro de que hablamos anteriormente.

Recogiendo a Hegel, Beuys se sitúa en el contexto dialéctico de la interconexión de todo lo que es en el mundo, pero lo argumenta desde la fuente de las imágenes mentales como foco englobador, en vez del Dios Creador que pro- ponía Hegel, y manteniendo el mismo plano de una Totalidad, un Todo dialéctico. “En el desarrollo humano todo es moldeado desde imágenes elementales artísticas, lo que significa que todo, tanto lo humano como lo científico, procede del arte"11. Otra frase similar sería: "Todo el desarrollo cristiano no ha tenido lugar en las iglesias, sino en la concepción científica" ${ }^{12}$.

Así pues, Beuys habla también de totalidades absolutas, la máxima agrupación que se presenta como una única unidad compleja pero indivisible. Lo científico en Beuys, léase lo que tiene una relación directa con la naturaleza, procede del arte, ese "Todo viene del caos"13 o, también, "Todo es escultura"14 y "Todo es política" 15 sitúan al pensamiento beuysiano directamente en el corazón del pensamiento hegeliano. El Todo directamente como Todo Absoluto. Viéndolo desde aquí en una similitud de uso del lenguaje entre Hegel y Beuys, en construcción de frases con estructuras básicamente idénticas, podemos entender la influencia que el filósofo ejerció en el escultor, independientemente de que fuera por él reconocida o no y teniendo en cuenta que era imposible su desconocimiento ya desde sus años de escolar. Podemos considerar, por tanto, que los Románticos en general, de los que Hegel es precursor, están entre una de sus más tempranas influencias aún desde el prerromanticismo hegeliano.

En Beuys, y en cierto modo se puede decir que es una extensión del pensamiento hegeliano, el Todo con mayúscula, el avance del conocimiento humano, viene definido y fundamentado por el arte. Beuys se asegura un enfoque fundacional e iniciático para el arte y para el artista, el creador que, aunque lo escribamos con minúsculas, tiene funciones y características semejantes a las del Dios Creador de la Totalidad Absoluta, sólo que, esta vez, dentro de una Totalidad Finita. Desde esta finitud, desde la obra, se definiría el Todo no sólo dentro del terreno artístico sino también de la Totalidad de lo existente que abarca el par dialéctico de (finito/infinito), que bien podría ser un prototipo de iniciador del movimiento. Beuys creía tan firmemente en la fuerza autocreadora del hombre sobre sí mismo y sobre el mundo que se veía empujado a hacer suyas frases como la del antropósofo Rudolf Steiner, otra de sus 
grandes influencias: "Todo lo que ha llegado a la Tierra lo han logrado generaciones de espíritu divino. Lo siguiente lo hará el hombre mismo"16. Se trata de una lectura sobre el par hegeliano pero esta vez al revés, desde lo finito, lo que el hombre haga como creador, hacia lo absoluto, la totalidad, consecuencia de haber aceptado el resultado espiritual que lo acercaba al creador; desde ahora el propio hombre va a autocrearse desarrollando sus capacidades al máximo a partir de una totalidad en la que se ve a sí mismo inscrito como el medio que le es propio.

Partir de las capacidades de cada hombre era la máxima para nuestro artista, como demostré en mi libro "Beuysiana"17. En el cap. IV del libro me ocupé de dar la traducción de las diferentes palabras utilizadas en alemán (alle, ganze) que se traducen como "todo" en castellano, así como de aclarar el error común al traducir como "Todos los hombres son artistas" su conocida frase "Jeder ist ein Künstler", que más bien significa en castellano "Cada cual es un artista", ya que hemos de tener en cuenta que "jeder" es un adjetivo contable. En general la razón del equívoco que supone traducir esta frase como "Todo hombre es un artista" viene dada por tomarla de la traducción previa del inglés en que se vierte como "Everyone an artist".

Así pues, cada cual individualmente tiene la capacidad en potencia para ser artista mediante el desarrollo de sus cualidades innatas. Descubrimos un claro antecedente a esta frase en Hegel cuando dice "los orientales sólo han sabido que uno es libre, el mundo griego y romano que algunos son libres, y nosotros que todos los hombres en sí somos libres, que el hombre es libre como hombre"18. Este hombre en proceso de humanización, aquél cuyo movimiento está en marcha, continuará luchando según Hegel hasta que ya no encuentre oposición en sí mismo, hasta que termine de realizarse como humano, hasta que desaparezca el segundo elemento dialéctico, la antítesis, lo que todavía se resiste. Entonces entrará en la costumbre y cesará su actividad, a no ser que esta vuelva a ser motivada por otro cambio polar estableciéndose otro par dialéctico.

Para Hegel lo más alto que el hombre ha de alcanzar es su Espíritu. Veremos en Beuys que, además de este objetivo aparecen otros más concretos enfocados desde el mundo del arte: "El que quiera solapar el materialismo sobre todos los problemas del mundo mata al hombre porque aplica un método correcto para una parte a la totalidad"19. Pero, además, Hegel resulta muy interesante como modelo de influencia beuysiana por su coincidencia con la máxima cristiana: "la esencia del espíritu es conocerse a sí mismo, saberse y producirse como lo que es" 20 . Por su parte, según Beuys "Todo lo que tiene que ver con lo espiritual, como lo ve cada uno, no lo corrijo"21 y esto tiene lugar en la "resistencia de lo otro contra la identidad". Una resistencia muy necesaria en el arte, dado que autores y espectadores nos reunimos en las obras de arte en calidad de "otros" iguales que comparten, junto con las piezas, un mundo real donde la alteridad es puente para llegar a lo beuysiano. Queda, además, señalar que el tema de la alteridad era muy discutido en la década de los 80 y 90 respecto al funcionamiento de los sistemas democráticos masificados en los medios de comunicación en los que la fortaleza del proyecto de yo consciente, proclamado por Beuys, llama la atención frente al yo disgregado que era el propio del sujeto postmoderno.

Es un Beuys recién salido de la guerra el que se abre a nuevas posibilidades de cambio en un momento en que el conjunto del país estaba viviendo una renovación completa. Pero este ciudadano de la moderna ciudad de Düsseldorf mantendrá para siempre las influencias más tradicionales recogidas en su pueblo natal de Kleve. La aportación beuysiana modificadora de las dos influencias que estamos tratando en éste trabajo, para adaptarla a su concepción de la escultura es, precisamente al contrario de lo que proponía en el Concepto Ampliado de Arte, una atomización de cada sujeto como un yo potencialmente creador unido al deber cristiano de hacernos cargo de nosotros mismos desarrollando el ser que cada uno somos como a su vez se corresponde con el individuo autoconsciente de finales del s. XX.

Precisamente en este punto hay que tener en cuenta la militancia de nuestro artista en la creación y evolución inicial del Partido Verde alemán reivindicando un lugar político y real para todo lo vivo en la Tierra en un momento de sentimiento 
de conquista global de la humanidad sobre el planeta. Quizá ahora, casi medio siglo después, se vea todo esto como una ingenuidad del sistema, ahora que los Verdes, extendidos por todos los países democráticos se han pervertido, políticamente hablando, y se han alejado fundamentalmente de sus intenciones iniciales y de lo que fue la propuesta beuysiana. Pero, para Beuys, el Todo implicaba que hubiera un lugar para todo lo existente, y en consecuencia, en el discurso político y en la realidad cotidiana de cada uno de los ciudadanos.

También Hegel, correspondiéndose con una visión que abarca el cristianismo, propone un hombre individualizado, en evolución más allá de lo que es ya de por sí, más allá de lo natural dado, hacia lo espiritual: "Todo individuo tiene en sí mismo un ejemplo más próximo. El hombre es lo que debe ser, mediante la educación, mediante la disciplina (...) tiene que hacerse a sí mismo lo que debe ser; tiene que adquirirlo todo por sí solo, justamente porque es espíritu, tiene que sacudir lo natural. El espíritu es, por tanto, su propio resultado"22. Haciendo juego con esta traigo otra frase de Beuys a propósito de la relación entre naturaleza y espíritu: "Toda naturaleza futura tendrá la marca del hombre en ella"23. Las dos frases no sólo se complementan y definen la evolución humana desde una vertiente consciente, además reflejan cómo cada cual, cada individuo, debe de hacerse cargo de sí mismo, responsabilizarse de sí él solo. Es precisamente en esta línea donde "Cada uno es un artista", como encabezaba Beuys su tesis artística con la que responde a la situación opuesta defendida por quien prefería hablar del arte. Para Beuys el artista se encuentra pleno de capacidades a desarrollar que ya vienen heredadas de una evolución adquirida en la base de una transformación espiritual y refinada.

La naturaleza, y no sólo la naturaleza beuysiana sino toda ella, está sufriendo siempre un proceso de transformación que en la obra de arte se convierte en proceso de materialización, de llevar hacia el material sensible, en el caso de Hegel, a la representación de la idea en el texto, y en el de Beuys, a la materialización tridimensional. Este es un proceso en que el filósofo y el artista trabajan con la intensidad apasionada de la creación para llevar más allá de lo natural a la obra de arte, traspasando estratigráficamente sus diferentes capas de realidad cada vez más alejadas de la materia. La materia va quedando bajo sucesivas coberturas cristalizadas formando capas superpuestas a modo de estratos geológicos que hemos de traspasar para entender el proceso de materialización o el conjunto del trabajo que un autor, cada autor, realiza a lo largo del tiempo en esas cristalizaciones superpuestas. Para llegar a la racionalización, a la comprensión de este entendimiento, Hegel propone el camino de la dialéctica como método válido para cortar transversalmente los conjuntos articulados situando en estos cortes a pares polares o Todos dialécticos que nos den una medida de los mismos mediante el establecimiento de puntos concretos de lectura.

El conjunto de este Todo dialéctico supone, finalmente, el planteamiento hegeliano una vez reunidos todos los Todos que, a su vez, constituyen cada una de las disciplinas de conocimiento entre las que se encuentra la del Todo del Arte. Hegel plantea una definición de naturaleza y su diferenciación de la acción que el sujeto ejerce sobre ella cuando la analiza, cuando se le acerca buscando entenderla. Entonces crea el par polar (naturaleza/cultura) de donde lo cultural viene a ser opuesto a lo natural, es decir, aquello que el hombre se encuentra todavía sin manipular por él mismo. Es evidente que, en el desarrollo de éste par de elementos opuestos, el resultado va a estar contaminado por los dos, de tal modo que ya no podrá ser más considerado natural, es decir, que siempre hay una tendencia al predominio de lo cultural, dialécticamente hablando.

El Todo dialéctico de que está compuesta la obra beuysiana está jalonado de una buena cantidad de obras de arte, dado que Beuys fue un artista especialmente prolífico. Pero hay que considerar que todas estas obras sin exclusión, y por mucho que hagan referencia a un material que se presentaba bajo condiciones diferentes anteriormente, están integradas por distintos materiales de tal modo que todas y cada una de las obras se inscriben con el par polar (materia/material) mediante el cual podemos hacer otra lectura dialéctica más. Como usuarios que somos de estas piezas, estamos pendientes de 
desarrollar los diferentes temas desde los pares polares que lo beuysiano y el conjunto del conocimiento occidental nos aportan, cuantos más analicemos mejor comprenderemos la pieza en concreto y su relación con el trabajo del artista, la relación con el medio que le rodea e incluso con nosotros mismos, en resumen el Todo Absoluto que supone el Ilamado Concepto Ampliado de Arte de Beuys.

En cualquier caso el "otro", la alteridad, sirve de puente para llegar a lo beuysiano, porque ambos se reúnen en lo real que es la pieza y lo hacen en calidad de "otros" iguales. El "otro" es para Beuys ese individuo semejante, por tanto con idénticas capacidades artísticas, o de volver de la muerte o de sobreponerse a las heridas de guerra... todo lo que el mismo Beuys ha sido a través de los sucesos de su vida. Desde esta definición de alteridad no es de extrañar que traigamos aquí otras definiciones de Hegel anteriores en el tiempo: "Todo lo finito tiene que superarse a sí mismo" 24 , complementando lo que ya hemos comentado sobre el momento determinado y finito, que se corresponde con la naturaleza y se trabaja según las propuestas de Hegel y de Beuys para alcanzar el espíritu o la totalidad absoluta más elevada. No hay que olvidar, como dijimos al principio, que entre ambos está otro filósofo también alemán aunque no reconocido como influencia directa de Beuys, se trata de Heidegger, cuyo pensamiento es cercano a la materia, a la tierra. Conviene recordarlo porque Beuys, como escultor, no deja de trabajar nunca con materiales concretos dentro del par (materia/material), aun y cuando el material pueda ser tan etéreo como el pensamiento.

Hegel cita desde el arte: "La representación de la unidad ya no se encuentra en el ser determinado natural, en el sol, en la luna, en las estrellas, en la montaña, en el río, sino que sólo es realizada en la medida en que ha pasado a través del espíritu y se ha mostrado como resultado de su trabajo. Este trabajo es el arte"25. Podemos decir tras esta frase que hay una coincidencia entre Hegel y Beuys respecto a lo definido como materialización de la obra artística, ya que, mientras Hegel llama al trabajo arte, Beuys habla de un trabajo de tamizar a través del espíritu, desde la naturaleza hacia lo absoluto pasando por los estratos geológicos superpuestos en que se halla el material y las características y condicionamientos que sean necesarios.

El material escultórico es aquello con que mantenemos un trato de iguales físicos a partir de nuestra existencia sobre la Tierra. Esta exterioridad, junto con la dirección que la dirige al mundo, hace que se cree un vector positivo de movimiento entre el ser y el mundo. El material está tan arrojado en el mundo como lo pueden estar los objetos que él mismo integra o, también, la parte más existencial de los sujetos y atendiendo a la manera en que Heidegger entendía el ser ahí, definido por él como "ser-en-el-mundo", algo que era arrojado fuera de sí mismo, de ser ontológico. Se trata de una existencia que responde a la filosofía existencial del sufrimiento frente al mundo, en el mundo, que coincide temporalmente con la etapa vital de Joseph Beuys, pero que no le influyó tanto como por ejemplo a Giacometti, 20 años mayor que él, o a otros artistas contemporáneos suyos que fueron llamados existencialistas.

A propósito, una cita de Beuys: "La encarnación de Cristo en las relaciones físicas de la tierra (...) Un suceso que cambia todo el mundo, hasta la materia"26. Se refiere a la Segunda Persona de la Trinidad también arrojado al mundo, encarnada, hecha materia viva, física, de tal modo que, defendiéndola, el cristianismo se refiere con cercanía a lo que se corresponde con la materia. Aquí se agranda el par (materia/material), se pone en movimiento como un foco más, otro par polar, para participar en el engendramiento de la Totalidad Absoluta que es la Santísima Trinidad, tanto como pueda serlo el Universo entero. Así pues, el material está sobre la Tierra y la materia, su referencia anterior y última, va más allá. Ésta materia ha sido entendida por algunos científicos como el verdadero creador, el Todo último donde todo halla su sitio. Nos encontramos otra vez entre el Todo Absoluto que es la Creación, Dios, y el Todo finito que es lo creado, que son ahora los objetos de nuestro alrededor y, por último, nosotros mismos.

Pues bien, ambos son imprescindibles para y después de la creación. Sirvan estas líneas como ampliación a la cita de Hegel que hacíamos unas páginas más atrás: "Sin el mundo, Dios no es 
Dios" y es que, entendiendo a Dios como Materia, también sin Materia, el Mundo no es el Mundo, ya que todo lo Material no podría establecerse como derivado de ella. Si la preocupación por el concepto de Dios, por todo lo relativo al Creador Último era fundamental hasta su sustitución por el yo creador (el hombre) desde el Romanticismo, hay que tener en cuenta la referencia más cercana que constituye Heidegger, quien entiende el Mundo de los objetos y los elementos creados por el hombre o simplemente existentes como él, a su alrededor. El Mundo con mayúsculas sería el Todo de lo que nos rodea, el conjunto de lo que nos acompaña, sea creado por nosotros como extensión que nos hace la vida más cómoda o sea como referencia existencial perteneciente a lo que habitualmente llamamos Naturaleza, es decir, nuestro ser más interno (entiéndase esta definición como diferente de la anterior, lo no manipulado por la mano del hombre).

Ambos, lo que creamos (naturaleza, recuérdese aquí la oposición dialéctica entre naturaleza y cultura) y la Naturaleza que somos, nos es vivido tan intrínsecamente que no podemos concebir nuestra existencia separada de ellos y por eso no es de extrañar reivindicaciones como las surgidas en los partidos verdes que dirigían su compromiso acentuándolo sobre el cuidado de estas relaciones. Ya Beuys recogía la herencia que le había acompañado desde niño junto con el amor a ciertos animales como la liebre o el cisne, símbolos de Kleve, o las discusiones más o menos filosóficas con los amigos con quienes formó el grupo cultural "Perfil de Sucesor". Todo esto no resultó sino un conato para el posterior modo de funcionar en su futura carrera artística, véase si no la mesa abierta al permanente diálogo que pone en la Documenta de 1972, donde una rosa en una probeta señalaba la reunión de naturaleza y ciencia en permanente transformación y evolución, tal y como correspondía a la Organización para la Democracia Directa creada por Beuys. En esta pieza puede verse el perfecto entendimiento que Beuys tenía de la realidad en continuo proceso de transformación, lo que Hegel había entendido, a su vez, como el carácter dialéctico de lo real: cada cosa es lo que es y sólo llega a serlo en relación, unión y dependencia con las otras cosas y, en último término, con la totalidad de lo real, en su continuo devenir y proceso, puesto que la realidad está en constante proceso de transformación y cambio.

Hegel, y después Beuys, siguiendo el modelo de pensamiento dialéctico, admiten que para mantener este motor constante están la propia contradicción interna de las polaridades. Cada realidad particular remite al todo y sólo puede ser explicada en relación con el todo. Este conjunto se expresa en la frase de Hegel: "Ella (la religión) no es la conciencia de esta o aquella verdad en los objetos particulares, sino de lo absolutamente verdadero, en cuanto universal, como aquello que lo abarca todo y fuera de lo cual no hay nada. Esto constituye así lo universalmente verdadero, que es en y para sí, se determina a sí mismo y no es determinado desde fuera. Mientras que lo finito necesita de otro para alcanzar su determinabilidad"27. Podríamos decir, a raíz de esta afirmación, que, para Hegel, "Lo verdadero es el todo", que hemos de entender establecido en torno a parámetros propios de la filosofía prerromántica moviéndose en torno a conceptos como Verdad o Absoluto y donde el de "Todo" no deja de ser sino uno más para acercar al Mundo y al Hombre, a esta filosofía esférica y total que es la hegeliana cuya característica fundamental, ya apreciable a primera vista, es que se completa a sí misma como un Todo Absoluto en cuyo interior se encuentran otras totalidades particulares de funcionamiento autónomo como es la del Arte.

Pues bien, Beuys hereda también este modelo de Hegel. Claro está que el uso que Beuys le da se va a presentar bajo el prisma del hacer en la escultura de la segunda mitad del s. XX $y$, para ello, aunque Hegel es un gran maestro del que copiar un modelo de pensamiento básicamente ya estructurado, él tiene que acoplarlo y darle continuidad dentro del suceder en la escultura del momento. Creo que aquí está el primer logro de Beuys, buscarse un sitio en el pensamiento alemán de postguerra y, después, haber sabido llevarlo a un panorama internacional aprovechando que su país, Alemania, estaba viviendo una etapa de expansión y crecimiento en influencias políticas, económicas y artísticas. Él mismo, desde los años de postguerra, cuando fue a estudiar a la Academia de Arte de Düssel- 
dorf, supo presentarse como una alternativa de formas nuevas para un pensamiento continuista, tal y como interesaba que se comportara un pueblo que había perdido la contienda, del que se esperaba arrepentimiento pero cuya recuperación se estaba favoreciendo por parte de los países aliados vencedores.

Beuys recoge el espíritu más cercano al cristianismo que podía aportar Hegel para dar el salto a escultor internacional y máximo representante alemán. He aquí la cita de Hegel: "El objeto es la verdad y necesita, no obstante, para ser verdadero, la autoconciencia que se haya fuera de él"28. Después de todo lo que llevamos dicho, ahora aparece esta palabra básica, la "autoconciencia", la conciencia reflexiva del individuo. En este caso está dicha por Hegel en el libro que fue publicado originalmente en 1925. No puedo asegurar que Beuys conociera la frase ni el libro, pero me atrevería a decir que su "Cada hombre es un artista" refiriéndose a que las posibilidades con que cuenta cada uno desde su nacimiento sólo por ser humano han de ser desarrolladas como un deber ineludible, patrimonio exclusivo del individuo consciente y responsable. $Y$ esto está en todo el trabajo de Hegel, no sólo en esta concentrada frase donde sobre todo hace referencia a la importancia del hombre como individuo creador, independiente del objeto pero a la vez razón de ser del mismo.

Pondré otros dos ejemplos de diferentes trabajos realizados por Beuys en piezas escultóricas. El primero calificado usualmente como perteneciente al arte conceptual: "Schneefall" ("Caída de nieve", de 1965), formado por tres ramas rectas a las que se les han cortado las ramitas adyacentes $y$, sobre ellas, un apilamiento de varias láminas de fieltro gris tapando uno de los extremos de las ramas.

El otro ejemplo podría ser el objeto que se presenta aislado en una vitrina, perteneciente al grupo de obras llamado "Block Beuys", que aún se presentan reunidas gracias a que un grupo de amigos del artista las recopilaron y mantuvieron así en el Museo de Darmstadt. En la habitación número 7 del Museo encontramos esta vitrina con uno de los trineos de la pieza mayor ya comentada "La manada". Tras los cristales se encuentra un auténtico trineo de madera firmado por Beuys en marrón Braunkreuz y con una cruz del mismo color, un rollo de fieltro gris atado con dos cintas blancas, una linterna y un trozo de grasa. Además, sobre la base de la vitrina, la pieza llamada "Badewanne", de 1961 ("Bañera"), que es una resistencia dentro de un recipiente metálico sobre un trozo de fieltro oscuro y al lado de un trozo amorfo de grasa.

El objeto para Beuys es un medio que trasciende sus pensamientos. Desde el principio de su andadura artística, Beuys se plantea ir más allá del material y lo mantiene, irrenunciable y universalmente, durante todo su trabajo dando lugar a lo que define como su Concepción de la Escultura. Una escultura que necesariamente ha de ser social y partir de la interacción entre los dos elementos del par polar (frío/calor); es decir, de la Temperatura como concepto escultórico a partir del cual mantener estrechas relaciones con materiales que fueran especialmente sensibles a estos parámetros, tales como la grasa, el fieltro, el chocolate, el cobre, el aluminio, el plomo... materiales cuyo estado es especialmente sensible a los cambios de temperatura.

Por tanto, no todo el material es característico de la escultura beuysiana, porque no todo material es posible para esta dinámica transformativa (frío/calor). La propuesta de Escultura Ampliada que hace Beuys se apoya en un material a su vez procedente de la materia, es decir, de algo anterior desde lo que se deriva. Se trata de un material cambiante dentro de la dinámica transformativa de la dialéctica, inmerso en un proceso de evolución entendido por Beuys a partir de la Temperatura generadora de los procesos dinámicos del mundo que constituyen su Teoría de la Escultura. Esta concreción en un par dialéctico como es (frío/calor) es, en definitiva, un proceso espacio-temporal que abarca el Todo, que en este caso se presenta bajo su propuesta de Teoría de la Escultura y lo centra desde uno de sus aspectos.

No conviene olvidar que Beuys había empezado su trabajo como escultor profesional (después de la guerra y antes de ir a la Academia de Düsseldorf) tallando maderas y yesos para tumbas en su zona natal. Su creciente interés por lo cambiante se extiende de los lugares típicos y específicos que favorecen su Concep- 
to de la Escultura hasta materiales novedosos entre los que también se encuentra el propio pensamiento, entendido igualmente en cuanto transformable con el paso reversible del frío al calor o viceversa. A propósito de su modelo de Escultura, Beuys dice que es semejante a las sociedades en que viven las abejas. Este pensamiento sería el material por excelencia de lo humano, "Todo llega a ser material escultórico y todo adquiere forma a través del pensamiento, por lo que el pensamiento es también tomado con un significado escultórico"29. La Escultura sale del hombre y es para el hombre, él es el usuario primero y último y la Escultura depende de él. Por tanto, la característica que reúne a los hombres es la de pensar y, consecuentemente, el pensamiento es definitorio de la Escultura beuysiana. Un pensamiento dinámico, en movimiento, entendido como positivo, como un acto de voluntad, un avance hacia adelante, los valores que marcan al hombre como humano han de desarrollarse en el futuro: "El futuro es, a mi entender, la dimensión que contiene el punto donde todo comienza" 30 . Beuys está hablando del tercer paso del movimiento dialéctico que encontramos, una vez más, avanzando hacia delante, hacia el futuro.

Consecuencia de esta misma preocupación por lo futuro, nacía en Alemania el partido de los Verdes y Beuys se presentaba como candidato a las primeras elecciones: "Toda la naturaleza futura tendrá la marca del hombre en ella", por tanto y en consecuencia con la nueva política, la responsabilidad con el planeta es otra de las totalidades que interesa a Beuys.

Los chamanes, y Beuys se considera uno de ellos, son aún, en las tribus más remotas, considerados como artistas, “El único (rincón) todavía no gastado, el del arte, desde un profundo pasado histórico, pero retorna como futuro, como una totalidad, la del hombre autoconsciente" ${ }^{\prime 31}$. La consciencia es lo que ganan tanto el chamán como el artista como resultado de su trabajo. Este futuro beuysiano tiene como antecedente el chamanismo que recogió entre sus influencias para utilizar recurrentemente como motivo en su trabajo. El chamán es el individuo capaz de ir y venir de experiencias extremas, como pudo ser para Beuys la de la guerra, abriendo caminos en la consciencia espiritual de la colectividad que le rodea desde su individualidad. Beuys dibuja chamanes femeninos y masculinos y proyecta el camino que recorren "hacia el futuro donde todo comienza"; su intención manifiesta es transgredir el mito de la muerte y comenzar una vida renovada. De esta manera Beuys entiende que ha de hacerse una síntesis entre el pasado y el presente para avanzar hacia el futuro con una idea clara sobre la evolución de nuestra propia naturaleza. "Había una autoridad, el sumo sacerdote, el rey o qué sé yo, que unió la cultura bajo el principio del todo, y el principio aplicado era la vida espiritual" 32 .

El hombre es la parte decisiva para la materialización de lo espiritual, pero también los animales son portadores de espiritualidad en diferentes escalas tal y como se ve en su acción "Cómo explicar cuadros a una liebre muerta" (realizada en la Galeria Schmela de Düsseldorf en 1965) en que el artista se embadurna la cabeza con láminas de oro y miel mientras sostiene en su regazo una liebre muerta, para él símbolo de la encarnación y el nacimiento, mientras que la miel es una energía viva, símbolo del pensamiento el cual, por el contrario y según Beuys, constituiría nuestra energía más muerta.

Respecto a otra rama diferente, pero enraizada también en sus preocupaciones, cuando él mismo es considerado en la línea del gran Romanticismo alemán por Bonito-Oliva: “El artista es el demiurgo que interviene en el interior de las fuerzas caóticas y que sustrae la materia en su estado magmático para transformarla y darle una forma" 33. Y es que, para Beuys, los valores del pasado se extienden progresando hacia adelante, así por ejemplo: "Contrastes como Calor-Frío, Dilatación-Contracción, Cuerpo-Alma, Actividad-Pasividad, podrían hacerse comprensibles, en una tematización como esa, como términos correspondientes a una totalidad. No son presentados como una dualidad dada, sino como polarización que siempre sugiere la situación de anulación de un equilibrio, en una relación de diálogo"34.

El punto de unión entre Hegel y los Románticos está aquí admitido por el propio Beuys. Al referirse a la historia del arte, la filosofía y la poesía, pero también la pediatría o la biología, 
o cualquier otra rama del conocimiento, el funcionamiento de lo artístico articula esta influencia integrándola mediante un corte transversal al Todo Absoluto, como vimos en la cita "Todo proviene del caos"12, cuyo epicentro para Beuys se halla en el arte. Un Todo de donde todo procede y a donde todo vuelve, cercano a la materia última y dentro de donde encontramos otras totalidades con el mismo funcionamiento, como corresponde al "Todo procede del arte". Beuys parece responder a tantas frases con la misma estructura con la pronunciación de otra de ellas: "Todo arte deriva de una forma u otra del primer Romanticismo"35.

El uso del pensamiento característico de todos los hombres aparece en la frase "Todo está en un flujo continuo" 36 , precisamente el flujo que domina también el movimiento llamado "Fluxus" en cuya primera etapa Beuys participó, a la vez que era profesor, junto con el músico Henning Christiansen activando diversos dispositivos y objetos y haciendo performances. Si cada artista participante en Fluxus lo hace de un modo diferente, también participa de distinta manera en el concepto antropológico del arte de Beuys su Concepto Ampliado de Arte.

Lo que viene del alma, en tanto circunstancia reclamada por los Románticos siglo y medio antes, vuelve a aparecer entre los intereses principales beuysianos para entender el arte y al artista. Ambos son una continuidad de lo sagrado que ha sido el arte de todos los tiempos, desde las imágenes pintadas en la cueva o las figuras esteatopígicas de la prehistoria hasta la enseñanza que recoge Beuys de su maestro Lehmbruck, quien le antecedió como avanzado en la escultura expresionista alemana de preguerra: "Protege la llama, porque si no se protege la llama, antes de que se dé uno cuenta el viento apagará la luz que él atizó" ${ }^{37}$. Beuys pronunció este discurso de agradecimiento a Lehmbruck durante la entrega que le hicieron del premio con este nombre en Duisburg el 12/1/1986 y en él explica la influencia que le acompañó toda su vida desde el encuentro casual de una foto de una escultura de este escultor poco antes de la guerra. Beuys ex- plica que Lehmbruck sólo puede ser entendido desde lo oyente, lo meditativo, lo volitivo, todas aquellas categorías nuevas de la escultura que le abrieron puertas para interesarse y dedicarse a este campo. Así entiende la recogida del testigo, de la llama de Lehmbruck, para la renovación del conjunto social a través de la Escultura.

Por cierto, que la metáfora de la llama no es casual para una escultura que se basa en la transformación producida por los cambios de temperatura. Pero, al mismo tiempo, la llama representa en la cultura cristiana al Espíritu Santo colocándose sobre cada individuo a modo de protección. Esto enlaza con el interés por la figura de Cristo, la encarnación materializada de la totalidad absoluta que es Dios vista desde fuera de la fe cristiana.

Si todo lo cambiante sobre la Tierra ha de pasar por la mano del hombre, este principio de evolución está recogido en el "Concepto Ampliado de Arte" de Beuys, un modelo más práctico que teórico donde pensar, sentir y querer (la voluntad) son los criterios estéticos, el principio de evolución humana que a Beuys le interesa desde el lema que propone a toda la sociedad, donde cada hombre va a ser artista en cuanto empiece a ejercitar las cualidades que le hacen humano. Y, a la vez, un hombre de su tiempo, heredero y difusor de las tradiciones que heredó desde niño y potenció reuniéndolas en su Concepto Ampliado del Arte, consistente en una verdadera ampliación dialéctica de la escultura que ejercitamos de manera casi automática, tan acostumbrados estamos a su funcionamiento bajo los parámetros de un diálogo dialéctico por ser nuestro modo de ejercitar el pensar desde el inicio de nuestro más inmediato pensamiento occidental. Beuys, con su enorme carisma y más que demostrada habilidad plástica, lo pondrá en movimiento a partir de una determinada Teoría de la Escultura que amplía en cuanto a efectos y referencias hasta crear, de un modo semejante a como Hegel había planteado con su pensamiento dialéctico, una Totalidad más compleja y Todo abarcante que es su Concepto Ampliado de Arte. 


\section{NOTAS}

${ }^{1}$ E. Bloch, Sujeto-Objeto. El pensamiento de Hegel, Fondo de Cultura Económica, Madrid, 1982, p. 144 (trad. del original alemán "SubjektObjekt Erläuterungen zu Hegel" en su edición de 1962 por Guillermo Hirata junto a Justo Pérez del Corral y por Jose $\mathrm{M}^{\mathrm{a}}$ Ripalda el cap. VI).

2 Ibidem.

${ }^{3}$ op. cit., 257.

${ }^{4}$ op. cit., 261.

${ }^{5}$ Oteiza propósito experimental, Fundación Caixa de Pensións, Madrid, 1988, p. $100, n^{\circ}$ de cat. 80.

${ }^{6}$ Joseph Beuys, MNCARS, Madrid, cat. exp. del 15 marzo al 6 de junio, 1994, p.77, n de cat. 27.

7 G. W. F., Hegel, El concepto de religión, Fondo de Cultura Económica, Madrid, 1981, p. 18 (trad. Del original "Vorlesungen über der Religion" establecida por George Lascon en su ed. de 1966 y trad. Por Arsenio Ginzo).

${ }^{8}$ E. Bloch, cap. "Filosofía del arte", op. cit., 256-291.

${ }^{9}$ op. cit., 135.

10 Vischer, Theodora, Beuys und die Romantik, Walther König, Köln, 1983, p. 44, "Alles ist, aber das Seyn wird".

${ }^{11}$ V. Harlan, R. Rappmann, P. Schata, Soziale Plastik, Achberger Verlag, Achberg, 1984, p. 17. "innerhalb der menschliche Entwicklung alles aus Elementaren Kunstvorstellungen heraus gebildet wurde, das heisst alles Menschliche, Wissenschaftliche stammt aus der Kunst".

${ }^{12}$ op. cit., p. 22. "Die ganze christliche Entwiclkung hat sich nicht in den Kirchen abgespielt, sondern im Wissenschaftsbegriff".
13 op. cit., 22, "Alles kommt aus dem Chaos".

${ }^{14}$ AA. VV., En torno a la muerte de Joseph Beuys. Necrologías, ensayos, discursos, Inter Nationes, Bonn, 1986, p. 61, (trad. de Rafael de la Vega).

${ }^{15}$ V. Harlan, W. Konnertz, K. Thomas, op. cit., p. 110: "Alles ist politisch".

${ }^{16} \mathrm{H}$. Bastian (editor), Joseph Beuys. The Secret Block for a Secret Person in Ireland, Schirmer/Mosel,München, 1988 , p. 35: "Alles was bis zu Erde gegangen Ist, haben göttliche Geistgenerationen geschaffen. Das, was folgen wird, wird Der Mensch selber machen".

17 M. Ortuzar, capítulo "Todo", Beuysiana, Servicio de Publicaciones Universidad de Vigo, 2011, pp. 27-33

${ }^{18}$ G. W. F. Hegel, Lecciones sobre la filosofía de la historia universal. Introducción General, Universidad de Valencia, Valencia, 1990, p. 46, trad. de José Gaos.

${ }^{19}$ H. Bastian, op. cit., p. 31: "Wer den Materialismus über alle Probleme der Welt stülpen will, tötet den Menschen $a b$, weil er eine sektorenhaft richtige Methodik anwendet auf das Ganze".

${ }^{20}$ G. W. F., Hegel, op. cit., p. 54.

${ }^{21}$ V. Harlan, R. Rappmann, P. Schata, op. cit.., 14: "alle Dinge, die mit dem Geistigen selbst zu tun haben, wie einer das sieht, das korrigiere ich nicht".

${ }^{22}$ G. W. F. Hegel, op. cit., p. 43.

${ }^{23} \mathrm{~J}$. Beuys, Aktive Neutralität, FIU, Freie Volkshochschule Argental, Wangen, 1989, p. 10: "Alle zukünftige Natur, jeder von nun an gepflanzte Baum, trägt die Merkmale des Menschen an sich".
${ }^{24}$ E. Bloch, op. cit., 132.

${ }^{25}$ G. W. F. Hegel, El concepto de religión, Fondo de Cultura Económica, Madrid, 1981, p. 309.

${ }^{26}$ H. Bastian, op. cit., p. 22: "Der Inkarnation des Christuswesens in die Physischen verhältnisse der Erde () die Ganze Welt verändert bis in die Materie hinein".

${ }^{27}$ G. W. F. Hegel, op. cit., p. 89

${ }^{28}$ op. cit., p. 321.

${ }^{29} \mathrm{C}$. Tisdall, Joseph Beuys, Thames \& Hudson, Nueva York, cat. de la exp. en Salomon Guggenheim Foundation, 1979, p. 86.

30 J. Beuys, H. Bastian, Jeannot Simmen, "Joseph Beuys, si nada dice nada, yo no dibujo", Pamiela, Pamplona, enero-febrero, $n^{\circ} 11,1986$, p. 23.

${ }^{31}$ AA. VV., op. cit., p. 47.

${ }^{2}$ V. Harlan, R. Rappmann, P. Schata, op. cit., p. 13.

${ }^{33}$ Bonito-Oliva, A., "Special Joseph Beuys", Artstudio, n 4, Abril, 1987, p. 85.

${ }^{34}$ Vischer, T., op. cit., p. 36: "Gegensätze wie Wärme-Kälte, Ausdehnung-Zusammenziehung, Körper-Seele, Aktivität-Pasivität können in solcher Thematisierung als jeweiliger Ausdruck einer Totalität verständlich gemacht werden. Denn sie sind nicht als gegebene Dualität presentiert, sondern in einer Polarisierung, die immer wieder den Zustand der Aufhebung in einem Gleichgewicht, einer dialogischen Beziehung suggeriert".

35 Jappe. G., "Special Joseph Beuys", op. cit., p. 11.

${ }^{36}$ V. Harlan, R. Rappmann, P. Schata, op. cit., p. 14: "alles ist in einem dauernden Fluss".

${ }^{37}$ AA. VV., op. cit., 1986, p. 65. 